\title{
Code mixing by a Non-ESL content instructor: The Language Choice and Syntactic Features
}

\author{
Norzie Diana Baharum \\ Academy of Language Studies \\ Universiti Teknologi Mara, Jengka, Pahang, Malaysia \\ Kamisah Ariffin \\ Academy of Language Studies \\ Universiti Teknologi Mara, Jengka, Pahang, Malaysia \\ Rahimah Abd. Wahab \\ Academy of Language Studies \\ Universiti Teknologi Mara, Jengka, Pahang Malaysia \\ email:norziediana@uitm.edu.my,kamisah@uitm.edu.my,rw6106@uitm.edu.my
}

DOI: https://doi.org/10.37134/ajelp.vol7.1.3.2019

Cite this article (APA): Baharum, N. D., Ariffin, K., \& Abd. Wahab, R. (2019). Code mixing by a Non-ESL content instructor: The Language Choice and Syntactic Features. AJELP: Asian Journal of English Language and Pedagogy, 7(1), 25-37. https://doi.org/10.37134/ajelp.vol7.1.3.2019

Abstract: A study on language alternation despite its pervasive presence in the academia, can never be exhaustive. Given the complexities of the geography in which the English language transcends many language boundaries, modern studies of code switching present various facets of this bilingualism phenomenon. Adding to this, the present study explores the employment of code switching (CS) by a non-English as Second Language (non-ESL) content instructor in a Malaysian tertiary institution that uses English as a medium. It looks at (i) the language choice and utterances, and (ii) the syntactical features of the code-switched lecture by this non-ESL content instructor. In addition, the main reasons for the instructor's language choice are also provided. A self-taped business studies lecture with a duration of 75 minutes is used for this study. The audio transcription then is categorised into 4 types of utterances namely (i) English, (ii) Malay (iii) Arabic and (iv) Code-Mixed. Syntactical analysis later groups the codemixed utterances into 11 syntactical categories which are pronoun, adverb, verb, conjunction, verb phrase, noun, noun phrase, adjective, determiner, tag question and interjection. The content analysis discovers Code-Mixed utterances as the most dominant feature of this lecture followed by English utterances. Descriptive analysis ranks the syntactical features of the codeswitched data in which pronouns are found to be the most switched item 
while Malay interjections like pulak and Ya Allah are switched the least. We conclude that code-switching used by this content instructor serves some pedagogical purposes which might bring positive effects to students. The institutional rigidity in seeing English as a medium of instruction should thus be renegotiated.

Keywords: Language Choice, Code Switching, Code Mixing, Malaysian NonESL Content Classroom.

\section{INTRODUCTION}

Code switching (CS) which is a form of language alternation is a unique bilingual phenomenon which has been under the scrutiny of numerous language scientists from all over the world. Since languages are considered to be a living organism which interacts symbiotically with the cultures and the people (Ortega, 2014; Jiang, 2000) a study of this form of language alternation thus cannot be exhaustive. The uniqueness of the linguistic features which are present in CS, the complex individual choices made when languages become alternated as well as the socio-cultural influences that shape a speaker's language alternation make this bilingual phenomenon worth exploring. Global CS studies have encompassed code switching in young children (Brice \& Anderson, 1999), school children (Benavides \& Medina-Jerez, 2017; Lehti-Eklund, 2012), school teachers (Chen \& Ting, 2016; Chowdhury, 2012; Gulzar, 2010), college students (Alenezi, 2010; Bista, 2010, Liu, 2010), college instructors (Ariffin \& Husin, 2011, Ahmad \& Jusoff), non-teaching professionals (Ariffin \& Rafik-Galea, 2009; Andita, 2013; Al Heeti \& Al Abdely, 2016) and many more. Researchers have also looked into its employment in bilingual parent-children reading interactions (Kabuto, 2010), the interaction between four generations of native Gibraltarians (Weston, 2012) as well as its use in digital interactions (Themistocleous, 2015).

Studies on the practice of code switching in Malaysian classrooms, to researchers' knowledge, are still scarce. This is especially true for tertiary non-ESL content classrooms which are expected to be fully conducted in English, following the language policy of the institution. Furthermore, investigation on the syntactic elements of the English-Malay code-mixed utterances in this tertiary setting has not yet been done thus far and the present study hopes to fill such gap. The present study particularly looks at the CS employed by a non-ESL content instructor whose practice of code switching in her business studies lecture could have been governed by different situational or/and linguistic needs. This investigation thus aims to look at these two things: the language choice of the non-ESL content instructor while delivering her business studies lecture and the syntactic features of her code-mixed utterances. The study hence aims to answer these two basic questions:

- What is the language choice of a non-ESL content instructor while delivering her lecture and why?

- What are the syntactic features frequently found in the non-ESL content instructor's codemixed utterances? 


\section{Defining Code Switching and Mixing}

Defining CS can be challenging because of its indefinite definition. This paper uses the general definition of CS by Brice and Anderson (1999, p.17) which is, languages alternation "within a single discourse, sentence, or constituent" (dialects too are included in the definition, see Gardner-Chloros, 2009; Grosjean, 2000). CS can be divided into inter-sentential CS and intrasentential CS (Poplack, 1980; Myers-Scotton, 1993) with the latter also known as code mixing (Grosjean, 1982; Torres, 1989 as cited in Brice et al, 1999).

The focus of this paper is the intra-sentential CS - a code mixing, which occurs when there is a mix of words, phrases, affixes and clauses from different languages within a sentence. The term CS nevertheless will be used as an umbrella term for the general discussion of this aspect of bilingualism. Code here refers to the two languages used by the instructor which are Bahasa Malaysia (L1) and English (L2). In the context of this study, English is the medium of instruction stipulated by the institution (UiTM) thus expected to be optimally used in most of the lessons. English therefore is what Meyers-Scotton (1993) termed as the matrix language (ML) the main language employed in code-switched utterances - and Bahasa Malaysia (L1) is the embedded language (EL), a language that serves a lesser role in CS.

\section{Code Switching: Various Discoveries}

Past studies make interesting discoveries of CS with researchers displaying mixed-reactions. The advocates of CS like Grosjean (1982, 2000, 2001), Poplack (1980), Gardner-Chloros (2009), Myers-Scotton (1993), Brice and Anderson (1999) and Skiba (1997) for instance view CS not as a language deficiency or an interference but rather a normal bilingual behaviour which serves various communicative functions. On the contrary, Cheng and Butler (1989) see CS as a language deficiency which, as put by Sanchez (ibid, p.298) "could take away the purity of the language".

Other findings derived from CS studies prove that this common aspect of bilingualism should not be viewed negatively. It provides ways for speech pathologists, for example, to better understand the linguistically-diverse children's unique language production. One such study is by Brice and Anderson (1999). Investigating CS in children, this longitudinal study on a Spanish-English girl found Spanish being the dominant utterances used in the participant's interaction with her Spanish-English speaking mother, with 201/2006 being code-mixed utterances. Nouns $(50.25 \%)$ are the most frequently found syntactic element in the code mixed data, followed by verbs (12.43\%) and verbal phrases $(8.89 \%)$. The least occurring element in the code-mixed utterances are adjectives $(2.98 \%)$. Brice et al opine that CS in children serves certain communicative strategies thus, it should not be penalized or treated as a child's linguistic deficiency. Nouns are also ranked the highest in the linguistic properties listed in Poplack's study (1980) of Hispanic adults with interjection coming second and preposition ranked last.

A CS study on trilingual children by Hoffman and Stavans (2007) also contributes interesting insights. The researchers found a steady increase of CS and CM occurrences in the daily discourse of English-Spanish-Hebrew speaking child participants from the age of three to six. As they grow older, their language alternation slowly decreases. The study also discovers the production of more $\mathrm{CM}$ than $\mathrm{CS}$ as the trilingual children aged, reflecting their increased "dominance in the three developing languages" (ibid, p. 61). The increased languages dominance found in older children, signaled through the bigger production of CM makes older bi/trilingual children "linguistically more sophisticated" as CM, opined by the researchers, demands "a more 
sophisticated type of bilingual competence and reveals the child's greater command of each linguistic system" (p.61). In addition, the study also discovers that the trilingual children's switches are mostly done between two languages (bidirectional) with only a few instances of trilingual switches appear. This finding, according to the researchers, may be attributed to the fact that trilingual switches are harder than bilingual switches as it involves more "structural robustness and permeability" (p.71).

Alenezi (2010) in his study on Kuwaiti college students' attitude towards classroom CS suggests the college's policy makers to consider Arabic-English code switching in their stipulated English-mediated classrooms. This is based on his findings in which students strongly prefer Arabic-English CS in order to better understand the occupational therapy subjects. In addition, professional contact with Arabic monolingual patients in the future is also cited as another reason for this preference. The employment of CS to achieve subject comprehension here is in line with what Ariffin and Husin (2011) reported in their study, involving diploma students from a Malaysian tertiary institution which requires English as a medium of instruction. Students with low English proficiency, according to the study, are "more tolerant to the instructor's CS/CM" (pg. 237). This is seen as helpful as their low proficiency of the language hinders their comprehension of the English teaching materials and lectures. The same results are aslso reflected in another study focusing on students with low English proficiency. Ahmad and Jusoff (2009) found that the instructor's CS provides students with better comprehension of various aspects of English such as vocabulary and grammatical rules. In addition, they also benefit psychologically as CS in the classroom, as claimed by many students, increases their learning satisfaction and reduces language learning anxiety.

A similar study but with a different student population (Malaysian secondary students) adds more to a pool of English-Malay codeswitching knowledge. Chen and Ting's (2011) investigation of Malaysian English and Science teachers' CS behavior reiterates the previous studies' findings. Teachers usually resort to English-Bahasa Malaysia CS when explaining terms and concepts for students' comprehension and giving instructions as to ensure students clarification of the steps involved, especially in laboratory works. It is also interesting to note that the study's triangulation of the audio-taped classroom sessions and informant reports discovers the fact that CS is employed unconsciously by most of the teacher-respondents. This leads to the researchers' belief that there is little need to impose strict adherence to the language used in the classroom as "most code switching occurs below the level of consciousness" (Chen $\&$ Ting, 2011, p.15). The notion of unconsciousness here echoes Grosjean's claim that "a bilingual rarely asks the conscious question, "Which language should I be using with this person?". (1996, p.4)

\section{METHODS}

\section{Participant}

The participant is a Business Studies lecturer who at the time of audio-recording has 8 years of teaching experience. She was invited to take part in the research and briefed on the procedures. The participant gave her consent to both: being audio-taped while giving her lecture and interviewed later, with a condition that the data would only be used for research purposes. The participant's L1 is Malay and English is her L2. 


\section{Procedures}

The participant was asked to self-tape her lecture for that particular session titled Business Growth Opportunities. She was informed that a natural delivery of the lecture was expected in order to see the actual use of language/s in a content-subject classroom. The length of the recording is 75 minutes. An audio self-taping was employed for the participant's convenience and a semi-structured interview was held later to gauge some insights with regards to the language choice in her lecture.

\section{Data Collection and Analysis}

The audio-taped lecture was transcribed verbatim by a research assistant. The main author then revised the transcription for accuracy. In the transcript, we applied a bold font for the use of language/s other than English and round brackets ( ) for an English translation with the translated items underlined. Parentheses were placed in square brackets [ ] to assist with the comprehension. We did not do grammatical editing for data authenticity. Data analysis involved frequency count of the utterances and the syntactic features found in the code-mixed samples.

We employed the general definition of utterance which is a continuous speech production with beginning and ending marked by a clear pause. The utterances were first categorized into four groups (i) English utterances, (ii) Malay utterances, (iii) Arabic utterances and (iv) Codemixed utterances. We excluded text book reading by the instructor as it does not constitute natural language production.

Following Chen and Ting's (2011) convention, we also did not consider the word "okay" as code-switching due to its widespread use in many other languages as to avoid overrepresentation of CS occurrences. For the same reason, words borrowed from the English language (i.e kos, produk, televisyen, psikologi, elemen, rekod, and stok) were also excluded from the analysis. The code-mixed utterances were then further analysed to determine the linguistic properties frequently found in this group of utterances. The rank of syntactic features established in this study is then compared to the ones proposed by Poplack (1980) and Brice and Anderson (1999).

\section{RESULTS AND DISCUSSIONS}

\section{Language Choice in a Lecture by a Non-ESL Content Instructor}

Our findings show that code switching is the main feature in this non-ESL content instructor's business studies lecture as her code-mixed utterances made up 48\% of the total 520 utterances. The switching was mainly done between English and Malay with one occurrence of EnglishArabic CS. This is followed by English utterances (41\%) and Malay utterances (10\%). There was one Arabic utterance (1\%) recorded when the instructor began her lecture with the Islamic greeting Assalamualaikumwarahmatullahiwabarakatuh. The use of an Islamic greeting as well as the English-Arabic switching as found by Ibrahim, Shah and Armia (2013) and Suan (1990 as cited in Ibrahim et al, 2013) is a normal feature in a discourse involving Muslims. Table 1 below provides the number of English, Malay, Arabic and code-mixed utterances as well as the total number of utterances found in the 75-minute-long-lecture. 
Table 1: English, Malay, Arabic and Code-Mixed Utterances and Total for the Lecture Session

\begin{tabular}{|c|c|c|c|c|}
\hline English & Malay & Arabic & Code-Mixed & Total \\
\hline 214 & 54 & 1 & 251 & 520 \\
$(41 \%)$ & $(10 \%)$ & $(1 \%)$ & $(48 \%)$ & $(100 \%)$ \\
\hline
\end{tabular}

In a country where English is either a second or foreign language, institutional language policy that stipulates English as a medium of classroom instruction can be a challenge. As CS can be common even in ESL/EFL classroom where teachers generally possess good language proficiency (see studies by Ahmad \& Jusoh, 2009; Chen \& Ting, 2011), CS occurrences in a non ESL content classroom such as the one studied can be anticipated. Higher degree of pressure of English-medium policy can be felt by the non-ESL content instructors and students whose level of English proficiency varies. This is true to this Business Studies instructor who attributes her CS mainly to her average English proficiency. She frequently code switches as found in the following extracts:

Extract 1: Let say, saya memang suka brand Panasonic.

(Let's say, I really like Panasonic brand)

Extract 2: I beli that Panasonic punya barang, berkualiti.

(I buy that Panasonic item, good quality)

Extract 3: So I will buy aaa kalau saya nak beli tv, I will choose for

Panasonic.

(So I will buy aaa If I want to buy [a] tv, I will choose

Panasonic)

Extract 4: Kalau saya nak beli aaa peti ais, washing machine, semua

saya akan pilih, maknanya semua saya akan pilih

Panasonic.

(If I want to buy aaa [a] fridge, washing machine... all I will

choose, it means all I will choose Panasonic)

In these extracts, the instructor's frequent code-switching can be seen even in her use of simple daily-life examples while explaining the concept of branding to students - an elaboration that can be easily done in English by an instructor with a high level of English proficiency. Extract 3 shows her hesitance to complete her sentence in English when she finally code switches to Bahasa Melayu "kalau saya nak beli TV", instead of the initial English phrase "So I will buy". Correcting herself through a better grasp of tenses, this instance of CS mirrors the issue of language competence as admitted earlier in our semi-structured interview. Language competence can be one of the factors influencing an instructor's confidence in delivering lectures in English, which can later lead to the effective lesson or the lack thereof - another issue pointed by our respondent during the interview.

Our finding reiterates the study by Ariffin and Husin (2011) who report instructors and students' language competence as one of the reasons for the former's frequent code switching in a classroom. In their comparison between proficient and less proficient instructors, the latter are found to code-switch more often than the former. Proficient instructors as reported, also give 
encouragement to students to improve their English through the instructors' optimal use of the language during lecture. Although the employment of CS in a classroom serves different pedagogical and social purposes and does not necessarily reflect the instructors' language proficiency, language competence issues faced by some non-ESL instructors are never to be ignored.

In addition to the reason above, the instructor's CS is also done to enhance students' understanding of the lesson through clarification. This is particularly true when it involves business terminologies as found in the following examples:

Extract 5: Ok, what is backward integration that aaa detergent, softener pun awak yang keluarkan.

(Ok, what is backward integration that aaa detergent, softener you provide too)

Extract 6: So this is horizontal integration, tadi macam mana dia boleh dapat aaa aaa strateginya adalah from customer loyalty.

(So this is horizontal integration, which gains aaa aaa, the strategy is from customer loyalty)

The need for classroom CS to assist students' comprehension has been cited in previous researches like the ones done by Ahmad and Jusoh (2009), Chen and Ting, (2011), Ariffin and Husin (2011), and many others. The examples from the two extracts above show this purpose as the instructor code-switches to Malay while explaining business terminologies, "backward integration" and "horizontal integration". Her frequent language switching thus is needed to achieve pedagogical purposes, as her students might not be able to comprehend monolingual lesson, especially when it involves these business jargon.

\section{Syntactic Features in the Non-ESL Content Instructor's Code-mixed Utterances}

The categorization of the code-mixed syntactic properties is shown in Table 2. Our descriptive analysis records the syntactic elements of the code-mixed utterances as presented in Table 3.

\section{Table 2: Taxonomy of the Code-Mixed Syntactic Features}

Syntactic
Features

\begin{tabular}{ll}
\hline Pronoun & $\begin{array}{l}\text { Because bukan mudah kita nak ubah people. (Because [it is] } \\
\text { not easy [for] } \underline{\text { us }} \text { to change people) }\end{array}$ \\
\hline Adverb & $\begin{array}{l}\text { Sebab as we getting more bigger, the management jugak akan } \\
\text { berubah. (Because as we [are] getting bigger, the management } \\
\text { too will change) }\end{array}$
\end{tabular}




\begin{tabular}{|c|c|}
\hline Verb & $\begin{array}{l}\text { Ok, let say from the total people yang hantar kain to the dobi, } \\
\text { aaa you get } 20 \% \text { from the market.( Ok, let's say from the total } \\
\text { people who send [their] laundry to the laundry, aaa you get } 20 \% \\
\text { from the market) }\end{array}$ \\
\hline Conjunction & $\begin{array}{l}\text { Ataupun you want to introduce the new product pun } \\
\text { impossible. (으 you want to introduce the new product [it is] } \\
\text { impossible too) }\end{array}$ \\
\hline Verb phrase & $\begin{array}{l}\text {...so you must know that aaa bila nak buka new branch... (... } \\
\text { so you must know that aaa when [you] want to open [a] new } \\
\text { branch...) }\end{array}$ \\
\hline Noun & $\begin{array}{l}\text { Ok, for example U-Mart, before this mmm bila kita nak beli } \\
\text { barang, aaa for groceries... (Ok, for example U-Mart, before } \\
\text { this mmm when we want to buy things, aaa for groceries...) }\end{array}$ \\
\hline Noun phrase & $\begin{array}{l}\text { Sebelum ni, aaa your profit maybe from } 1 \text { to } 2 \text { ringgit, your } \\
\text { profit adalah seringgit je. (Before this, aaa your profit maybe } \\
\text { from } 1 \text { to } 2 \text { ringgit, your profit is only one ringgit) }\end{array}$ \\
\hline Adjective & $\begin{array}{l}\text { Still the services sama, your company same, sama. (Still the } \\
\text { services [are the] same, your company [is the] same) }\end{array}$ \\
\hline Determiner & $\begin{array}{l}\text { Haa! bila dah ada banyak branches, ok what are the new } \\
\text { position that... (Haa! when you have got many branches, what } \\
\text { are the new position that...) }\end{array}$ \\
\hline Tag Question & $\begin{array}{l}\text { Tapi as a body wash, as a soap ok, } \underline{\text { kan? }} \text { ( } \underline{\text { But as a body wash, as }} \\
\text { a soap [it is] ok, } \underline{\text { isn't it?) }}\end{array}$ \\
\hline Interjection & $\begin{array}{l}\text { Ya Allah, the other class pun sama jugak. (Ya Allah, the other } \\
\text { class [did] the same too) }\end{array}$ \\
\hline
\end{tabular}

Table 2 presents our categorization of the syntactical features found in the code-mixed utterances which are pronoun, adverb, verb, conjunction, verb phrase, noun, noun phrase, adjective, determiner, tag question and interjection. The code-mixed utterances here are put in a bold font and underline is applied for examples of the syntax. For instance, the word "kita", which contextually means "us" falls under pronoun while "jugak" which means "too" is categorized as adverb. 
Table 3: Syntactic Elements of the Code-Mixed Utterances by Three CS Studies

\begin{tabular}{lll}
\hline Poplack (1980) & Brice \& Anderson (1999) & $\begin{array}{l}\text { Baharum, Ariffin \& Abd } \\
\text { Wahab (2018) }\end{array}$ \\
& & \\
\hline 1.Single noun & 1. Subject/Object Noun & 1. Pronoun \\
2.Object noun phrase & 2. Verb & 2. Adverb \\
3.Interjection & 3. Verb phrase & 3. Verb \\
4.Phrase & 4.Prepositional phrases and & 4. Conjunction \\
5.Independent clause & Adverb & 5. Verb Phrase \\
6.Subordinate clause & 5.Articles & 6. Noun \\
7. Subject noun phrase & 6. Adjectives & 7. Noun Phrase \\
8.Conjunction & & 8. Adjective \\
9.Adverb & & 9. Determiner \\
10.Verb Phrase & & 10. Tag Question \\
11. Verb & & 11. Interjection \\
\end{tabular}

Table 3 compares the syntactical elements of the code-mixed utterances between our study and two previous studies of code-switching. It is found that the ordering of syntactic elements established in the present study differs greatly from the ones proposed by Poplack (1980) and Brice and Anderson (1999). In our study, the most frequently alternated item is Pronoun which makes up $21.7 \%$ of the total 932 code-mixed syntactic items. It is followed by Adverb (15.5\%), Verb (13.6\%), Conjunction (12.8\%), Verb Phrase (12.7\%), Noun (8.15\%), Noun Phrase (3.74\%), Adjective (3.02\%), Determiner (1.28\%) Tag Question (1.06\%) and Interjection $(0.32 \%)$. This is against Poplack's (1980) syntactical order which lists Single Noun as the most switched syntax and Verb as the least switched. Our syntactical order also differs greatly from Brice and Anderson's as their study finds Subject/Object Noun as the most frequently switched syntactical feature with Adjectives being the least alternated.

There are a few possible reasons that can be suggested for the present findings. The main one being that the nature of the study itself focuses mainly on the classroom code switching - an instructional setting where elaboration, clarification, and message reiteration dominate the discourse as to achieve pedagogical objectives. Unlike the studies by Poplack (1980) and Brice and Anderson (1999) which are based on conversational switching of Spanish bilingual adults and children respectively, the speech samples of this study are gathered from a business studies content lecture delivered by a Malay instructor whose pedagogic role and L1 display distinctive features. As we can see, her most frequently switched items, which are Malay pronouns (i.e saya/I, kita/we/us, awak/you, mereka/they, mereka punya/their) are mainly found in her lecture. This fits the pedagogical setting as the switched-items are mainly employed while she elaborates the lesson, provides clarification of new business vocabularies and gives examples to students. The following excerpts show this:

Extract 7: And it exists mmm for example in Facebook, we have one pages, saya tak ingat lah laman page tu, aaa we register with them, aaa sebagai ahli.

(And it exists mmm for example in Facebook, we have one pages, I cannot remember that site page, aaa we register with them, aaa as a member) 
Extract 8: $\underline{\text { Kita kena bayarlah, annual fee dia. }}$

(We have to pay its annual fee)

Extract 9: At the same time, kita boleh jual jugak pada...people outside...outsiders.

(At the same time, we can also sell to... people outside...outsiders)

The same goes for her switching to Malay adverbs (i.e selalunya/usually, pun/juga/too), verbs (i.e menawarkan/offers, ada/have) and conjunctions (i.e kalau/if, dan/and, sebab/because) which mainly occur in her elaboration of the lesson.

\section{Table 4: English Words with the Malay Particles and Sample Extracts

Particle "lah" inserted Particle "kan" inserted

do-lah/ payment-lah/ forward

integration-lah/that's why-lah/ confirm- settle-kan/ compare-kan/ finish-kan

lah/ yourself-lah/comparison-lah/ taxes-

lah/ potential-lah

Extract 10:

This is the most aaa common market penetration strategy yang selalunya aaa company do lah. (This is the most aaa common market penetration strategy [a] company always do lah)

\section{Extract 11:}

Haa! so you must settlekan within that time. (So you must settle [the work] within that time)

In addition, the other syntactical feature of the English-Malay code switching from the lecture is the usage of Malay particles such as "lah" and "kan", as presented in Table 4. Despite them having no particular meaning, the emotive function of these particles, according to Kuang (n.d, p.148) is necessary to convey "different intentions, motives and moods, of the speakers" - a unique identity deemed inseparable from Malaysian English. Our findings suggest that these particles are mainly used as subconscious markers thus echoing the findings by Ibrahim et al (2013). As Malay particles are common in giving emphasis and confirmation (Suan, 1990 as cited in Ibrahim et al, 2013) we can see that our subject's insertion of these "lah" and "kan" particles to some English words like "comparison", "taxes" and "settle", is mostly unconsciously done for the same purposes - a habit resulting from a strong L1 influence. 


\section{CONCLUSION}

The findings of this study mirror some of the real classroom practice despite a clear English medium policy stipulated by the institution. The use of mainly code-switched utterances by our subject (48\%) poses some challenges as to what extent classroom CS is needed by the instructors to achieve teaching and learning goals. Another matter that needs to be highlighted is whether or not CS can be more tolerated in a non-ESL content classroom where students' comprehension of the content subject rather the language used is of utmost importance. As our subject's classroom language choice is shaped by her average English proficient as well as her students', it invites a myriad of questions - amongst the first is, the kind of language supports the instructor and students might need from the institution in order to achieve both, an adherence to the policy, as well as pedagogic objectives.

As the present study is limited to only one sample lecture, more studies on classroom code-switching should be carried out. For instance, comparative studies with expansive samples can be done between the use of CS in ESL and English content classrooms or the use of CS in science and technology classrooms as to better understand this bilingual production. Future studies should also involve instructors with different L1 and various degree of English proficiency as to respond to the question of whether or not the practice of code- switching signals one's linguistic deficiency.

\section{ACKNOWLEDGEMENT}

This study was funded by the Ministry of Higher Education (Malaysia) and Universiti Teknologi MARA (UiTM) under the Research Acculturation Grant Scheme (RAGS) 600-RMI/RAGS 5/3 $(119 / 2014)$

\section{REFERENCES}

Ahmad, B. H., \& Jusoff, K. (2009). Teachers' code-switching in classroom instructions for low English proficient learners. English Language Teaching. 2 (2), 49-55.

Al Heeti, N. H. \& Al Abdely, A. A. (2016). Types and functions of code-switching in the English language used by Iraqi doctors in formal settings. International Journal of Advanced Research and Review. 1 (8). 10-18. Retrieved from https://www.researchgate.net/publication/306031490

Alenezi, A. A. (2010). Students' language attitude towards using code-switching as a medium of instruction in the college of health sciences: An exploratory study. ARECLS, 7, 1-22.

Andita, P. D. (2013). Code switching in Indonesian Idol 2012 program: A case study of the judges' comments and the viewers' attitudes. Passage, 1 (2), $99-108$.

Ariffin, K., \& Husin, M. S. (2011). Code-switching and code-mixing of English and Bahasa Malaysia in content-based classrooms: Frequency and attitudes. The Linguistics Journal. 5 (1), 220-24.

Ariffin, K., \& Shameem, R. G. (2009) Code-switching as a communication device in conversation. Language \& Society. 5 (9), 145-204.

Benavides, R. \& Medina-Jerez, W. (2017). No puedo "I don't get it": Assisting Spanglish-speaking students in the science classrooms. Retrieved from https://www.researchgate.net/publication/315758059

Bista, K. (2010). Factors of code switching among bilingual English students in the university classroom: A survey. English for Specific Purposes World. 9 (29). 1-19 
Brice, A. \& Anderson, R. (1999). Code mixing in a young bilingual child. Communication Disorders Quarterly, 21 (1), 7-22.

Chen, D. \& Ting, S. H. (2011). Researching code switching in teacher classroom discourse: Questioning the sufficiency of informant report. Language, Society \& Culture. 33, 8-18. Retrieved from https://www.researchgate.net/publication/233224500

Cheng, L. \& Butler, K. (1989). Code-switching: A natural phenomenon vs language deficiency. World Englishes, 8 (3), 93-309.

Chowdhury, N. (2012). Classroom code switching of English language teachers at tertiary level: A Bangladeshi perspective. Stamford Journal of English. 7, 40-61. http://dx.doi.org/10.3329/sje.v7i0.14462

Gardner-Chloros, P. (2009). Code Switching. Cambridge. Cambridge University Press. Retrieved from https://books.google.com.my/books

Grosjean, F. (1982). Life with two languages: An introduction to bilingualism. Cambridge: Harvard University Press.

Grosjean, F. (1996). Living with two languages and two cultures. In Parasnis, I. (Ed.). Cultural and Language Diversity and the Deaf Experience. Cambridge: Cambridge University Press.

Grosjean, F. (2001). The bilingual's language modes. In Nicol, J. (Ed.). One Mind, Two Languages: Bilingual Language Processing. Oxford: Blackwell.

Gulzar, M. A. (2010). Code-switching: Awareness about its utility in bilingual classrooms. Bulletin of Education and Research. 32 (2), 23-44.

Hoffman, C., \& Stavans, A. (2007). The evolution of trilingual codeswitching from infancy to school age: The shaping of trilingual competence through dynamic language dominance. International Journal of Bilingualism, 11 (1), 55-72. DOI: 10.1177/13670069070110010401

Hughes, C. E., Shaunessy, E. S., Brice, A. R., Ratliff, M. A., McHatton, P. A. (2006). Code switching among bilingual and limited English proficient students: Possible indicators of giftedness. Journal for the Education of the Gifted. 30 (1), 7-28.

Inbar-Lourie, O. (2010). English only? The linguistic choices of teachers of young EFL learners International Journal of Bilingualism, 14 (3), 351-367.

Jiang,W. (2000). The relationship between culture and language. ELT Journal, 54 (4), 328-334, https://doi.org/10.1093/elt/54.4.328

Kabuto, B. (2010). Code-switching during parent-child reading interactions: Taking multiple theoretical perspectives. Journal of Early Childhood Literacy. 10(2). 131-157. DOI: $10.1177 / 1468798409345109$.

Kuang, C. (2017). The implications of lah, ah, and hah as used by some speakers in Malaysia. Journal of Modern Languages, 14 (1), 133-153. Retrieved from https://jml.um.edu.my/article/view/3801

Lehti-Eklund, H. (2012). Code-switching to first language in repair - A resource for students' problem solving in a foreign language classroom. International Journal of Bilingualism, 17 (2), 132-152. DOI: $10.1177 / 1367006912441416$

Liu, J. (2010). Teachers' Code-Switching to the L1 in EFL Classroom. The Open Applied Linguistics Journal, 3, $10-23$.

Meyers-Scotton, C. (1997). Duelling Languages: Grammatical Structure in Code Switching. Clarendon. Oxford University Press. Retrieved from https://books.google.com.my/books.

Navracsics, J. (Interviewer) \& Grosjean, F. (Interviewee). (2002). Interview on Bilingualism [Interview transcript]. Retrieved from http://www. francoisgrosjean.ch/interview_en.html.Ortega, L. (2014). Understanding Second Language Acquisition. London, Routledge. Retrieved from https://books.google.com.my/books.

Poplack, S. (1980). Sometimes I'H start a sentence in Spanish Y TERMINOE EN ESPÂANOL: Toward a typology of code-switching. Linguistics, 18, 581-618. Retrieved from https://yorkspace.library.yorku.ca/xmlui/bitstream/handle/10315/.../CRLC00161.pdf 
Skiba, R. (1997). Code switching as a countenance of language interference. The Internet TESL Journal, 3 (10). Retrieved from http://iteslj.org/Articles/Skiba-CodeSwitching.html

Themistocleous, C. (2015). Digital code-switching between Cypriot and Standard Greek: Performance and identity play online. 19 (3). 282-297. DOI: 10.1177/1367006913512727

Weston, D. A. (2012). Code-switching variation in Gibraltar. International Journal of Bilingualism. 17 (1). 3-22. DOI: $10.1177 / 1367006911429526$ 